\title{
Rationalization in Australian Vocational Education and Training
}

\author{
Richard Skiba \\ LRES Training Management, Melbourne, Australia \\ Email address: \\ richard@skiba.com.au
}

\section{To cite this article:}

Richard Skiba. Rationalization in Australian Vocational Education and Training. International Journal of Vocational Education and Training Research. Vol. 6, No. 1, 2020, pp. 17-27. doi: 10.11648/j.ijvetr.20200601.13

Received: June 1, 2020; Accepted: June 12, 2020; Published: June 20, 2020

\begin{abstract}
This paper aims to examine qualification rationalization processes in Vocational Education and Training internationally to establish lessons learned such that they can be applied to the Australian system. Current interest in rationalization in Australia is being driven by research undertaken by the Department of Education, Skills and Employment, and promoted by the Australian Prime Minister, Scott Morrison.. They suggest that the current system is difficult to understand and use, and outline that the system would benefit from a reduction in the number of qualifications currently on offer. Zero or minimal uptake is the most commonly documented approach to qualification rationalization internationally and is most effective when paired with a process of stakeholder consultation and engagement. Effective consultation should be inclusive of training providers, enterprises, social partners, employment services, public authorities and research organisations to ensure qualifications on offer meet industry and social needs. Care should be taken to ensure rationalization does not deplete flexibility in the system that has intentionally been embedded to allow qualifications to match workplace requirements. The benefits in ensuring units of competency and qualifications are promptly updated and adapted to emerging needs rather than rationalized are noted. The 'updating' approach could be paired with an education program for users of the system and a program of stakeholder marketing to ensure that the system is fully understood by all those who use it.
\end{abstract}

Keywords: Vocational Education and Training, Qualifications, Rationalization, Reform, Training, Flexibility

\section{Introduction}

The Australian Chamber of Commerce and Industry [1] notes that currently a criticism of the Vocational Education and Training (VET) system is that there are too many qualifications and further note that in many qualifications there are very few enrolments. They suggest the reason for the limited uptake in many qualifications it that they are not related to current jobs. This observation has also been made by the Council of Australian Governments (COAG) agreement on a new shared vision for VET which articulated three priority areas, namely relevance, quality and reliability, articulated in the Vocational Education and Training (VET) Reform Roadmap Consultation Draft created by the Department of Education, Skills and Employment [2]. A number of priorities for reform in the Australian VET system were identified within the draft, one of which is to "streamline existing training package arrangements, including reducing the number of training products" [2]. This recommendation has been made as one related to establishing trusted and relevant qualifications and credentials and has a basis in a review of the current offerings within the Australian VET system.

The Department of Education, Skills and Employment [2] quantify that there are over 1,400 qualifications and almost 17,000 units of competency listed with training.gov.au, the National Register on Vocational Education and Training (VET) in Australia. Training.gov.au is the authoritative source of Nationally Recognised Training (NRT) which consists of Training Packages, Qualifications, Units of competency, Accredited courses, and Skill sets [3]. Of this collection of training products, they are seen to be "complex, highly prescriptive, and require extensive and continuous review" [2], and simplification of the system could lead to better meet learning and employer needs.

In his address to the National Press Club Prime Minister Scott Morrison stated that the large number of qualifications available to prospective students can be "bewildering and 
overwhelming" [4]. Prime Minister Morrison indicated that there are currently over 1400 qualifications on offer and almost 17,000 units of competency. In the context of a changing world of work, the Department of Education, Skills and Employment [2] suggests that it is crucial that qualifications "continuously adapt to meet the changing needs of the Australian workforce allowing qualifications and credentials to respond, with agility, to learner and employer needs". There should, however, be a developed set of competency standards, which can be viewed as 'occupational skills standards, in place for each job where VET level skills are relevant [1]. These should remain packaged as units of competency and qualifications. Given the current interest in qualification rationalization, consideration needs to be given to possible rationalization models, particularly in light of international experiences and how these could influence the Australian VET system. The rationalizing of qualifications refers to the process of combining similar qualifications and the removal of qualifications no longer required [5].

\section{Method}

This study reviews a range of available literature to examine mechanisms by which VET providers rationalize their qualifications in an international arena. These findings are then considered in light of the Australian VET sector with a view to identifying possible approaches for rationalization. The exploration is based on the notion that identifying the processes through which countries reform qualifications can provide examples of applications to wider VET systems, such as the Australian VET system.

\section{Discussion}

\subsection{European and Australian Vocational Education and Training Systems}

The European Training Foundation [6] highlights that there is no universal definition of what a qualification is, with variance in definition from country to country. In Australia, the VET system offers qualifications where participants can gain career-focused skills that are sought by employers. These are offered to those who are seeking to enter the workforce for the first time or re-enter the workforce after absences. Likewise the system is used by those who wish to re-train into a new job role or simply to upgrade skills. Participants in the system may also use it as a means for moving into further study in the higher education system. VET training providers deliver course programs in a range of formats and environments including both in real and simulated work environments. Training providers within the system include Technical and Further Education (TAFE) Institutes, private colleges, and many other schools and universities.

Upon completion of vocational training in Australia, students are awarded an Australian Qualifications Framework (AQF) based Certificate or Diploma. The qualifications framework includes certification at Certificate I, II, III and IV, Diploma, Advanced Diploma, Graduate Certificate and Graduate Diploma level qualifications within the VET sector. Certificates I and II provide students with basic vocational skills and knowledge, preparing them for employment, and can be seen as entry level qualifications. Certificates III and IV comparatively have largely replaced the range of traditional trade certificates and include, particularly at Certificate IV level, preparation for a range of supervisory roles. Diploma and Advanced Diploma level qualifications offer training preparing individuals for a range of management roles.

Training packages form a foundation for Registered Training Organisations, industry, employers and learners in Australia's system of competency-based training. Training packages include sets of competency standards and qualifications developed collaboratively by industry. A training package does not prescribe how the training should be delivered, nor the time taken to deliver it and this responsibility rests with training providers who crate training and assessment strategies to meet their stakeholder requirements [7].

Skiba [8] compares the Australian Qualification Framework to the European Qualification Framework and the national qualifications systems that exist within the frameworks. Within the European system, National Qualifications Frameworks (NQFs) classify qualifications by level, based on learning outcomes outlining what the holder of a certificate or diploma is expected to know, understand, and be able to do [9]. Skiba [8] notes that the Regulated Qualifications Framework (RQF) was developed in the UK in 2015, replacing the NQF and Qualifications and Credit Framework (QCF). The RQF is similar to the NQF and QCF, in that qualifications are still assigned 'levels' according to their difficulty. Essentially, the European and Australian vocational qualifications systems share many similarities allowing for reasonable comparison where reforms have been implemented. Internationally, as examples, competency-based systems include the British national vocational qualifications, the French professional certificate (certificat de qualification professionelle), the Estonian professional qualifications, and the Vocational Qualifications Authority (VQA) qualifications in Turkey [6]. Lessons learned through reforms in VET systems internationally may be of relevance to the Australian VET system on this basis, and particularly given that the purpose of the system, irrespective of where it is applied, is to prepare learners for work in specific occupations.

\subsection{Reform in Vocational Education and Training}

The European Training Foundation [6] discussed reforms undertaken to improve education and training to better align to the actual demand of competence from employers as a continuous process. They outline that these reforms are based on consideration of both occupational standards and educational standards and note that all partner countries have reformed. The reform has been executed "unevenly, 
sporadically and sometimes chaotically" [6]. A further finding of the study is that clear definition of different qualification types makes it easier to develop individual qualifications.

Shared definitions can provide a common architecture providing for development of qualifications of that type. As an example, the European Training Foundation [6] provides that Ireland uses four different types of qualification identified as major qualifications, minor qualifications, special purpose qualifications and supplemental or additional qualifications. Similarly, in Australia qualifications align to major qualifications fully covering the requirements of an occupation, minor qualifications can be delivered as individual units of competency, skills sets equate to special purpose qualifications and supplemental or additional qualifications are covered by accredited courses. These types of definitions are common in VET systems internationally and, as noted by European Training Foundation [6], they may be easiest way to start qualifications development with fairly straightforward qualification types, particularly where occupational standards and vocational qualifications are linked clearly.

The European Training Foundation [6] refer to unitization as a basis for qualification development. They also note that unitization, being where qualifications can be constructed sets of partial qualifications, or units, can make qualifications flexible. They do, however, warn that an excessively open architecture, where the combinations of units are endless, can lead to a high number of qualifications that can become hard to recognise. Finding the right balance is crucial for the development of meaningful vocational qualifications. The Department for Education [10] through its review of post-16 qualifications at level 3 and below in England noted that multiple qualifications of different types addressing similar occupational skills areas were offered. They further identified a number of related problems in the system including that the VET system is difficult to understand where students and employers unclear on skill levels and intended outcomes delivered by different qualifications. Sometimes these qualifications vary in size and often within the same level. They also found that the large number of available qualifications fails to support the growth in skills that individuals and the wider economy require.

Frontier Economics [11] establish a framework for effective qualification design with promotion of four basic principles, which they collectively referred to as RRRI characteristics. Qualifications should be recognizable in so far as allowing stakeholders to easily identify the holder's level of skill. They should also be rigorous such that holders of the qualification meet a required standard. Qualifications must be responsive where content remains relevant and responds positively to changes to employer and learner demands. The final suggested principle is that qualifications are innovative allowing for awarding organisations to improve how they meet current or expected demand. The RRRI characteristics should be considered a foundation for qualification development, irrespective of the VET system in which they reside.

Industry and employer engagement can be utilized to contribute to the development and review of qualifications inclusive of the RRRI characteristics. The European Training Foundation [6] notes that with regard to this type of employer engagement, "representatives from the world of work", such as employers and industry representatives, are experts of the competences that are needed on the job. They do not always, however, understand the implications for learning. Qualification design and reform then, must include a broad range of stakeholders, including regulators, trainers and assessors, industry experts, employers, unions and other interested parties. Misko [5] presents that across many systems in the EU the setting of occupational standards and educational standards for VET involves the formal participation of the social partners such relevant industry/professional bodies, trade unions, government representatives and in some countries community groups and students. The broad consultation approach as applied in the EU aligns with the desired approach for Australian VET as stated by Prime Minister Morrison [4].

\subsection{Rationalizing Qualifications}

Misko [5] identifies that the Scottish Qualifications Authority and the New Zealand Qualifications Authority have some clear directions about when and how qualifications are reviewed and removed. As an example, Misko provides that the Scottish Qualifications Authority has a 'zero uptake' policy where an accreditation committee removes the accreditation of any qualifications that have no uptake and where there is no clear justifiable evidence from the awarding body of candidate demand for the qualification for a period of two years. In the UK, there is a similar system for rationalizing qualifications for funding purposes by examining low- and zero-uptake qualifications. The New Zealand system includes a formal review process that can result in qualification removal. The New Zealand approach uses a system of review to ensure that qualifications remain fit for purpose.

A significant component of the review within the New Zealand rationalizing approach is mapping existing qualifications to current and future workforce needs and roles. There is also an onus on the qualification developer to identify any roles that are no longer current or which are being phased out, new roles which do not currently have a qualification, and qualifications that are not matched to a role or skill set [5]. Best practice then is inclusive of not simply removing qualifications for rationalization, but rather includes a holistic review to determine whether existing and emerging qualifications can be integrated into other existing qualifications. This can include provision of flexibility in current qualifications to absorb others, particularly where there is a high degree of similarity or lead to same or comparable job outcomes.

Misko [5] summarizes that the two-year low- or zero-uptake criteria have been identified for New Zealand, Scotland and the Skills Funding Agency of the Department of 
Business, Innovation and Skills in the United Kingdom. The Department for Education in the UK announced that more than 5,000 qualifications in England may no longer receive funding from August 2021 [12] under this approach. This approach could be utilized in other systems, however, as Misko [5] notes, it is important to understand that there may be 'niche' occupations that do not require a high uptake of qualifications. Any number of qualifications may be required as critical job roles even though there are limited participants. Any mechanism would have to take this into account.

\subsection{An Alternative Perspective}

In Australia, there are 68 training packages which containing more than 17,000 units of competency, 1,450 qualifications and 1,300 skill sets [13]. There are also 750 accredited courses which contain more than 3,550 units of competency and modules. Training packages are developed accessing a process of national consultation with industry, and they contain nationally recognised qualifications required for particular occupations. In doing so, competency standards are established for those particular occupations, including units of competency that outline the standards of performance required in the workplace and definitions of qualifications. Currently, in training package development:

"The AISC draws on advice from its network of more than 60 Industry Reference Committees (IRCs). The IRCs are made up of people with experience, skills and knowledge of their particular industry sector and are responsible for developing training packages that meet the needs of Australian Industry" [13].

The development process is also supported by Skills Service Organisations (SSOs) who are independent, professional service organisations that assist IRCs in their work developing and reviewing training packages. On this basis, Training Products in Australia are and have been developed through wide consultation with a broad range of stakeholders. The system is developed in this way to ensure that all stakeholders are able to contribute to the development of relevant qualifications that are reflective of industry practices and needs. Engagement of a broad range of stakeholders ensures that competency standards developed in Australia specify standards of performance but also aim to specify best and safe practice in that performance.

The tremendous number of units of competency developed in the Australian system demonstrate not only the diversity in work roles in Australia, but also the variance and complexity in those job roles. The system recognises that many jobs are not merely generic and in order to be performed safely, they require specific skills, knowledge and training. The system also highlights the level of commitment of the various stakeholders in documenting the profiles of the jobs to best train and protect their workers. Each of the 17,000 plus units of competency have been developed based on an identified need and review systems are in place to ensure their currency, although these may be delayed processes and slow to respond to market needs as noted by Scott Morrison [4].

The Department of Education and Training [13] notes that
Registered Training Organisations use training packages to design learning programs and strategies that assist people to gain, or to demonstrate that they possess, the skills and knowledge specified in units of competency. Training programs are then based on nationally endorsed competency standards that should be reflective of industry needs. The significant number of qualifications and units of competency in the system provide for a high degree of flexibility, particularly given that packaging rules for qualifications generally allow for selection of electives such that the program can be tailored to specific needs.

There is not necessarily an issue with large numbers of defined qualifications and units of competency in a vocational education and training system, as it is still up to registered training organisations to select the programs they run and this should be undertaken in consultation with the communities and industries they service. The more choices the various stakeholders have, the better a program can be matched to a specific work situation. Issues related to the use of the available qualifications may be related to misunderstandings by the stakeholders, such as training organisations and employers, that utilize them. An effective education program to outline the correct use of the system, in this case, would be more effective than a rationalization approach. In this regard, the Business Council of Australia [14] recommends provision of improved market information such that learners know what jobs are available, what they might earn, what qualifications are available and how much it will cost them.

A National Centre for Vocational Education Research study [15] noted that an effective strategy for supporting learners includes being flexible in the delivery of programs such that they are delivered where students feel most comfortable. This includes having access to a range of adaptable and flexible programs that can be tailored to learners' and industry needs as required.

\section{Conclusion}

Vocational qualifications provide the definition of the skills and knowledge for the stakeholders that use them. On this basis, the definition must be developed by the stakeholders to ensure the system of qualifications meets the relevant stakeholder requirements. This includes the design and application of the qualification. The collaboratively produced definition of what a qualification entails includes expectations of qualification outcomes, relevance to destination job roles, implementation responsibilities and scope of the qualification. As condoned by Misko [5], stakeholders and should include training providers, enterprises, social partners, employment services, public authorities and research organisations. Qualification rationalization similarly requires high levels of stakeholder engagement despite the methodology applied. The most commonly applied approach to rationalization is based on zero or minimal uptake models inclusive of stakeholder consultation to ensure key or industry specific required qualifications are not removed. 


\section{References}

[1] Australian Chamber of Commerce and Industry. (2019). Submission to the Vocational Education and Training Review. Australian Chamber of Commerce and Industry. Retrieved from

https://www.australianchamber.com.au/wp-content/uploads/20 19/02/AusChamber_Submission_VETReview_Jan-2019_Fina 1.pdf.

[2] Department of Education, Skills and Employment. (2020). Vocational Education and Training (VET) Reform Roadmap Consultation Draft. Retrieved from https://docs.employment.gov.au/documents/vocational-educati on-and-training-vet-reform-roadmap-consultation-draft.

[3] Department of Employment, Skills, Small and Family Business (2020). About training.gov.au. Retrieved from https://training.gov.au/Home/About.

[4] ABC News (Australia). (2020, May 26). PM looks to overhaul industrial relations in wake of COVID $19 \mid$ ABC News. [Video]. YouTube. https://www.youtube.com/watch?v=XIvJ6Gn497Y.

[5] Misko, J. (2015). Developing, approving and maintaining qualifications: selected international approaches. NCVER, Adelaide.

[6] European Training Foundation. (2014). Making Better Vocational Qualifications: Vocational Qualifications System Reforms in ETF Partner Countries. European Training Foundation. Retrieved from https://www.etf.europa.eu/sites/default/files/m/3AE7DF56862 00FCEC1257CA00047FD58_Making\%20better\%20vocationa $1 \% 20$ qualifications.pdf.

[7] National Centre for Vocational Education Research. (2007). Did you know? A guide to vocational education and training in Australia. NCVER: Adelaide, South Australia.

[8] Skiba, R. (2020). Adaptation of Australian Qualifications in Building and Construction for Delivery within the European
Qualifications Framework. International Education and Research Journal, 6 (5), 6-9.

[9] European Centre for the Development of Vocational Training. (2020). National qualifications frameworks (NQFs). Retrieved from

https://www.cedefop.europa.eu/en/events-and-projects/project s/nationalqualifications-framework-nqf.

[10] Department for Education. (2019). Review of post-16 qualifications at level 3 and below in England: interim impact assessments. Retrieved from https://consult.education.gov.uk/post-16-qualifications-review -team/post-16-level-3-and-below-qualifications-review/suppor ting_documents/Post $\% 2016 \% 201$ evel $\% 203 \% 20$ and $\% 20$ below $\% 20$ qualifications $\% 20$ review $\% 20 \% 20$ Impact $\% 20$ Assessment s.pdf.

[11] Frontier Economics/DfE. (2017). Assessing the Vocational Qualifications Market in England. Retrieved from https://assets.publishing.service.gov.uk/government/uploads/s ystem/uploads/attachment_data/file/629694/Assessing_the_V Q_market.pdf.

[12] UAL Awarding Body. (2020). DfE funding withdrawal for low-uptake qualifications. Retrieved from https://www.arts.ac.uk/partnerships/ual-awarding-body/stories /dfe-funding-withdrawal-for-low-uptake-qualifications.

[13] Department of Education and Training. (2020). Fact Sheet: training Products. Retrieved from https://www.myskills.gov.au/media/1772/back-to-basics-traini ng-products.pdf.

[14] Business Council of Australia. (2018), Future-proof: Australia's future post-secondary education and skills system, Retrieved from https://d3n8a8pro7vhmx.cloudfront.net/bca/pages/4386/attach ments/original/1542258016/LoRes-2018_BCA_EDUC_Futur e_Proof_WIP1A_\%281\%29.pdf?1542258016.

[15] Lamb, S, Maire, Q, Walstab, A, Newman, G, Doecke, E \& Davies, M 2018, Improving participation and success in VET for disadvantaged learners, NCVER, Adelaide. 